\title{
Coccidioidomicose pulmonar em caçador de tatus*
}

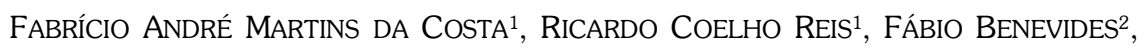 \\ Geraldo de Sousa TOMÉ ${ }^{3}$, Marcelo AlCÂNTARA HolandA ${ }^{4}$
}

\begin{abstract}
A coccidioidomicose, uma doença fúngica adquirida através da inalação do agente Coccidioides immitis sob forma de artroconídio, vem sendo descrita desde 1892. Restringe-se principalmente a áreas de clima árido, solo alcalino e regiões de baixo índice pluviométrico. Não por acaso, a maioria dos casos descritos no Brasil ocorreu na região Nordeste. Relata-se o caso de um homem de 19 anos, imunocompetente, com queixa de dor pleural bilateral, febre, adinamia e tosse seca havia dois meses.

A radiografia de tórax evidenciou múltiplos nódulos bilaterais. $\mathrm{O}$ paciente participava de caçadas a tatus (Dasypus novemcinctus) e a pesquisa direta para fungos no escarro evidenciou Coccidioides sp.

Tratado com anfotericina $\mathrm{B}$, apresentou pneumotórax e insuficiência respiratória, indo a óbito. A biópsia pulmonar post mortem evidenciou Coccidioides immitis sob a forma de endósporos.
\end{abstract}

(J Pneumol 2001;27(5):275-278)

\section{Pulmonary coccidioidomycosis in a armadillo hunter}

Coccidioidomycosis is a disease caused by inhalation of arthrospores of the fungus Coccidioides immitis. It has been recognized as a clinical entity since 1892. It is related to activities that involves dust exposure. It is found in many regions of the western hemisphere with dry and alkaline soil. In Brazil it has been described almost exclusively in the Northeast region where drought periods may favor its growth in its soil. We report a case of fatal coccidioidomycosis, in an immunocompetent host, associated to the activity of armadillo hunting (Dasypus novemcynctus) in a rural area of Ceará state.

Descritores - Coccidioidomicose. Exposição ocupacional. Tatus. Key words - Coccidioidomycosis. Occupational exposure. Armadillos.

\section{INTRODUÇÃO}

A coccidioidomicose, doença fúngica adquirida pela inalação (sob forma de artroconídio) do Coccidioides immitis, é sabidamente relacionada à exposição a poei-

* Trabalho realizado no Serviço de Pneumologia do Hospital de Messejana, Fortaleza, Ceará.

1. Médico Residente.

2. Médico Assistente do Serviço de Pneumologia.

3. Professor Titular do Departamento de Patologia e Medicina Legal da Universidade Federal do Ceará.

4. Doutor em Pneumologia pela Unifesp; Coordenador da Residência de Pneumologia.

Endereço para correspondência - Fabrício André Martins da Costa, Rua Lauro Maia, 331 - 60055-210 - Fortaleza, CE. Tel. (85) 2262940.

Recebido para publicação em $15 / 12 / 00$. Aprovado, após revisão, em 17/3/01.

J Pneumol 27(5) - set-out de 2001
Siglas e abreviaturas utilizadas neste trabalho

BAAR - Bacilo álcool-acidorresistente

BK - Bacilo de Koch

HIV - Vírus da imunodeficiência humana

ELISA - Enzime-linked immunosorbent assay

ras de solos áridos e semi-áridos de várias regiões do Hemisfério Ocidental bem como a diversas atividades exercidas nesses locais (e.g.: caçadas a roedores) ${ }^{(1)}$. Sua forma pulmonar, na maioria das vezes, é autolimitada, podendo evoluir para cronicidade e disseminação.

Há um número reduzido de casos publicados no país, mais precisamente, 12 casos até $1997^{(2)}$ (Quadro 1). O presente relato descreve um caso de coccidioidomicose em paciente jovem que adquiriu a doença através da exposição ao agente após caçadas a tatus.

\section{Relato do CASO}

Homem de 19 anos, agricultor, procedente de Boa Viagem, região de clima semi-árido no Estado do Ceará, sadio até havia dois meses, quando passou a apresentar 
dor pleurítica bilateral, acompanhada dois a três dias após por febre (não mensurada), adinamia intensa e tosse seca. Foi encaminhado ao nosso serviço, onde realizou radiografia de tórax, que mostrou múltiplos nódulos pulmonares bilaterais.
A bacterioscopia, pesquisa de BAAR e culturas para BK e germes piogênicos no escarro foram negativas, assim como as culturas e pesquisa de fungos em lavado broncoalveolar. Hemoculturas não demonstraram quaisquer microorganismos. Foram realizadas ainda duas sorologias

\begin{tabular}{|c|c|c|c|c|c|c|c|c|}
\hline \multicolumn{9}{|c|}{$\begin{array}{c}\text { Quadro } 1 \\
\text { Descrição dos casos de coccidioidomicose registrados no Brasil (LILACS) }\end{array}$} \\
\hline Autor/ano & Local $^{\dagger}$ & $\begin{array}{l}N^{0} \text { de } \\
\text { casos }\end{array}$ & $\begin{array}{l}\text { Idade/ } \\
\text { sexo }\end{array}$ & $\begin{array}{l}\text { Achados } \\
\text { clínicos }\end{array}$ & $\begin{array}{l}\text { Achados } \\
\text { radiológicos }\end{array}$ & Diagnóstico & Tratamento & Evolução \\
\hline $\begin{array}{l}\text { Gomes et al., } \\
1978^{(7)}\end{array}$ & Parapiranga-BA & 1 & 28/M & $\begin{array}{l}\text { Tosse seca e hemop- } \\
\text { tise }\end{array}$ & $\begin{array}{l}\text { Radiografia: opacidade } \\
\text { com cavitação em lobo } \\
\text { inferior esquerdo }\end{array}$ & $\begin{array}{l}\text { Lobectomia in- } \\
\text { ferior esquerda }\end{array}$ & Cirúrgico & $\begin{array}{l}\text { A ssin to mático } \\
\text { três anos após ci- } \\
\text { rurgia }\end{array}$ \\
\hline $\begin{array}{l}\text { Vianna et al., } \\
1979^{(8)}\end{array}$ & Piauí & 1 & $35 / M$ & Epigastralgia & $\begin{array}{l}\text { Radiografia: múltiplos } \\
\text { nódulos bilaterais al- } \\
\text { guns calcificados }\end{array}$ & $\begin{array}{l}\text { Biópsia pulmo- } \\
\text { nar }\end{array}$ & $N R^{*}$ & NR \\
\hline $\begin{array}{l}\text { Wanke et al., } \\
1994^{(1)+t}\end{array}$ & O eiras-PI & 3 & $\begin{array}{c}10 / M \\
N R\end{array}$ & $\begin{array}{l}\text { Manifestações febris e } \\
\text { respiratórias }\end{array}$ & NR & $\begin{array}{l}\text { Cultura de es- } \\
\text { carro }\end{array}$ & NR & NR \\
\hline $\begin{array}{l}\text { Kuhl et al., } \\
1996^{(9)}\end{array}$ & Crato-CE & 1 & $74 / M$ & Disfonia progressiva & $\begin{array}{l}\text { Radiografia sem altera- } \\
\text { ções. Obs: laringosco- } \\
\text { pia mostrou formação } \\
\text { polipóide em prega vo- } \\
\text { cal esquerda }\end{array}$ & $\begin{array}{l}\text { Biópsia de póli- } \\
\text { po em prega } \\
\text { vocal }\end{array}$ & $\begin{array}{l}\text { Cetoconazol } \\
\text { inicialmente e } \\
\text { anfotericina B } \\
\text { durante evolu- } \\
\text { ção }\end{array}$ & $\begin{array}{l}\text { Ó bito em 1992, } \\
\text { três anos após } \\
\text { diagnóstico (cau- } \\
\text { sa não definida) }\end{array}$ \\
\hline $\begin{array}{l}\text { Martins et al., } \\
1997^{(10)}\end{array}$ & Rio de Janeiro-RJ & 1 & & $\begin{array}{l}\text { Leucemia linfoblástica } \\
\text { aguda e quadro pul- } \\
\text { monar }\end{array}$ & & & & Ó bito \\
\hline $\begin{array}{l}\text { Silva et al., } \\
1997^{(5)+t}\end{array}$ & Aiuaba-CE & 4 & $\begin{array}{l}\text { 1) } 19 / M \\
2) 13 / M \\
3) 22 / M \\
4) 27 / M\end{array}$ & $\begin{array}{l}\text { De maneira geral: dor } \\
\text { torácica, febre, tosse, } \\
\text { dispnéia e adinamia }\end{array}$ & $\begin{array}{l}\text { Radiografias de tórax: } \\
\text { 1) condensações bilate- } \\
\text { rais extensas com áreas } \\
\text { de cavitação. 2) con- } \\
\text { densações alveolares } \\
\text { poupando apenas ápi- } \\
\text { ces. 3) similar ao ante- } \\
\text { rior 4) normal }\end{array}$ & $\begin{array}{l}\text { Pesquisa direta } \\
\text { e cultura do es- } \\
\text { carro }\end{array}$ & $\begin{array}{l}\text { 1) Itraconazol } \\
\text { 2) Expectante } \\
\text { 3) Expectante } \\
\text { 4) Sintomático }\end{array}$ & $\begin{array}{l}\text { 1) Abandono do } \\
\text { tratamento. De- } \\
\text { mais casos: assin- } \\
\text { tomáticos }\end{array}$ \\
\hline $\begin{array}{l}\text { Martins et al., } \\
1997^{(2)}\end{array}$ & $\begin{array}{l}\text { Monte Santo-BA } \\
\text { (reside em } \\
\text { São Paulo } \\
\text { há oito anos) }\end{array}$ & 1 & $22 / M$ & $\begin{array}{l}\text { Hemoptise, adinamia, } \\
\text { febre e infecções res- } \\
\text { piratórias }\end{array}$ & $\begin{array}{l}\text { Radiografia: infiltrado } \\
\text { reticulonodular e cavi- } \\
\text { dades em lobo superior } \\
\text { direito. TC: infiltrado in- } \\
\text { tersticial e cavitação de } \\
\text { paredes espessadas em } \\
\text { lobo superior direito }\end{array}$ & $\begin{array}{l}\text { Culturas de es- } \\
\text { carro, lavado } \\
\text { broncoalveolar } \\
\text { e testes soroló- } \\
\text { gicos }\end{array}$ & $N R$ & NR \\
\hline $\begin{array}{l}\text { Costa et al., } \\
2000 \\
\text { (presente } \\
\text { relato) }\end{array}$ & Boa Viagem-CE & 1 & $19 / M$ & $\begin{array}{l}\text { Febre, dispnéia, perda } \\
\text { de peso }\end{array}$ & $\begin{array}{l}\text { Radiografia: infiltrados } \\
\text { nodulares bilaterais. TC: } \\
\text { nódulos com cavitações } \\
\text { de paredes finas, bilate- } \\
\text { rais }\end{array}$ & $\begin{array}{l}\text { Pesquisa direta } \\
\text { em escarro e } \\
\text { biópsia pulmo- } \\
\text { nar post mor- } \\
\text { tem }\end{array}$ & Anfotericina B & $\begin{array}{l}\text { Ó bito após pneu- } \\
\text { motórax espontâ- } \\
\text { neo durante trata- } \\
\text { mento }\end{array}$ \\
\hline $\begin{array}{l}\text { † A quase tota } \\
\text { †† Relatos ond } \\
* \text { Não relatad }\end{array}$ & $\begin{array}{l}\text { dos casos desc } \\
\text { sos foram diagn }\end{array}$ & pre & jiões & & tes às do presente rela & & & \\
\hline
\end{tabular}




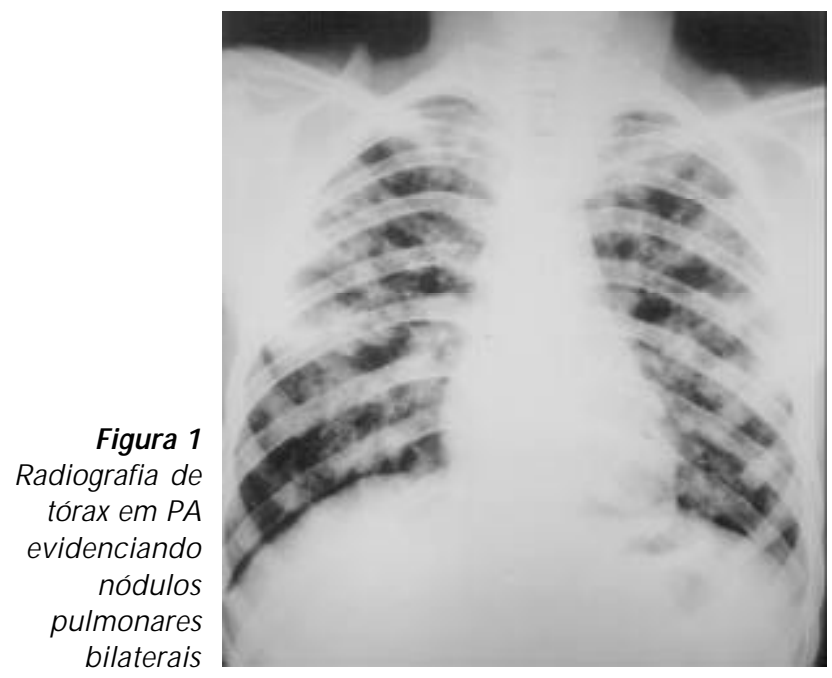

para HIV (método ELISA), ambas negativas. Fez uso de oxacilina e gentamicina, tendo sido associado itraconazol ao esquema devido à persistência de febre. Recebeu alta com remissão do quadro clínico e radiológico.

Aproximadamente um mês após os primeiros sintomas evoluiu com febre, dispnéia intensa e perda de peso não quantificada, tendo sido readmitido com quadro radiológico similar ao anterior (Figura 1).

O paciente participava ocasionalmente de caçadas a tatus (Dasypus novemcinctus), a última delas cinco dias antes do início do quadro. Relatava que um primo, também participante das caçadas, apresentara quadro clínico semelhante ao seu, no mesmo período, mas com resolução espontânea dos sintomas.

Encontrava-se em estado geral grave, taquipnéico, $(\mathrm{f}=$ 30irpm), febril $\left(\mathrm{T}=37,8^{\circ} \mathrm{C}\right)$, normotenso, com semiologia cardíaca sem alterações. À ausculta pulmonar apresentava murmúrio vesicular rude com crepitações inspiratórias discretas, disseminadas. Não encontramos alterações em exame físico de pele e abdome. Exames colhidos na admissão mostravam: leucócitos $=3.950 / \mathrm{mm}^{3}$, $\mathrm{pH}=7,54 ; \mathrm{PaCO}_{2}=32 \mathrm{mmHg} ; \mathrm{PaO}_{2}=71 \mathrm{mmHg} ; \mathrm{HCO}_{3}^{-}$ $=27 \mathrm{mEq} / \mathrm{L}$, com SaO $2=98 \%$. Realizou tomografia computadorizada de tórax, que evidenciava múltiplos nódulos com cavitações de paredes finas bilaterais (Figura 2).

No segundo dia de internação, a pesquisa direta para fungos no escarro mostrou Coccidioides $s p$. Anfotericina $B$ endovenosa foi administrada, com remissão da febre e melhora do estado geral. No 11 dia de internação apresentou insuficiência respiratória devido a pneumotórax espontâneo, necessitando de ventilação mecânica, evoluindo para óbito 24 horas após admissão em unidade de terapia intensiva.

Biópsia pulmonar post mortem evidenciou Coccidioides immitis sob forma de endósporos (Figura 3).

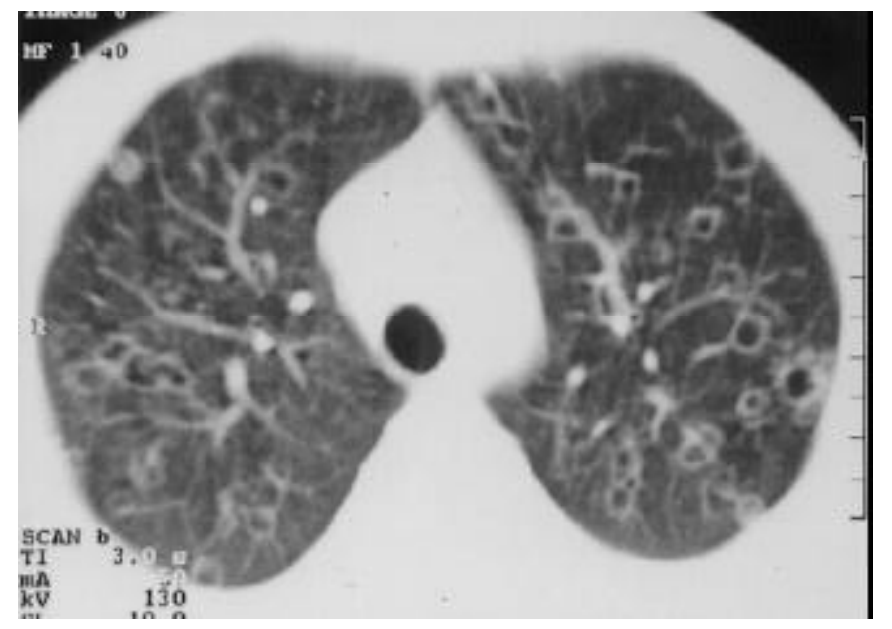

Figura 2 - Tomografia computadorizada de tórax mostrando nódulos, alguns com cavitações de paredes finas bilaterais guardando relação com vasos pulmonares, sugerindo disseminação hematogênica da infecção

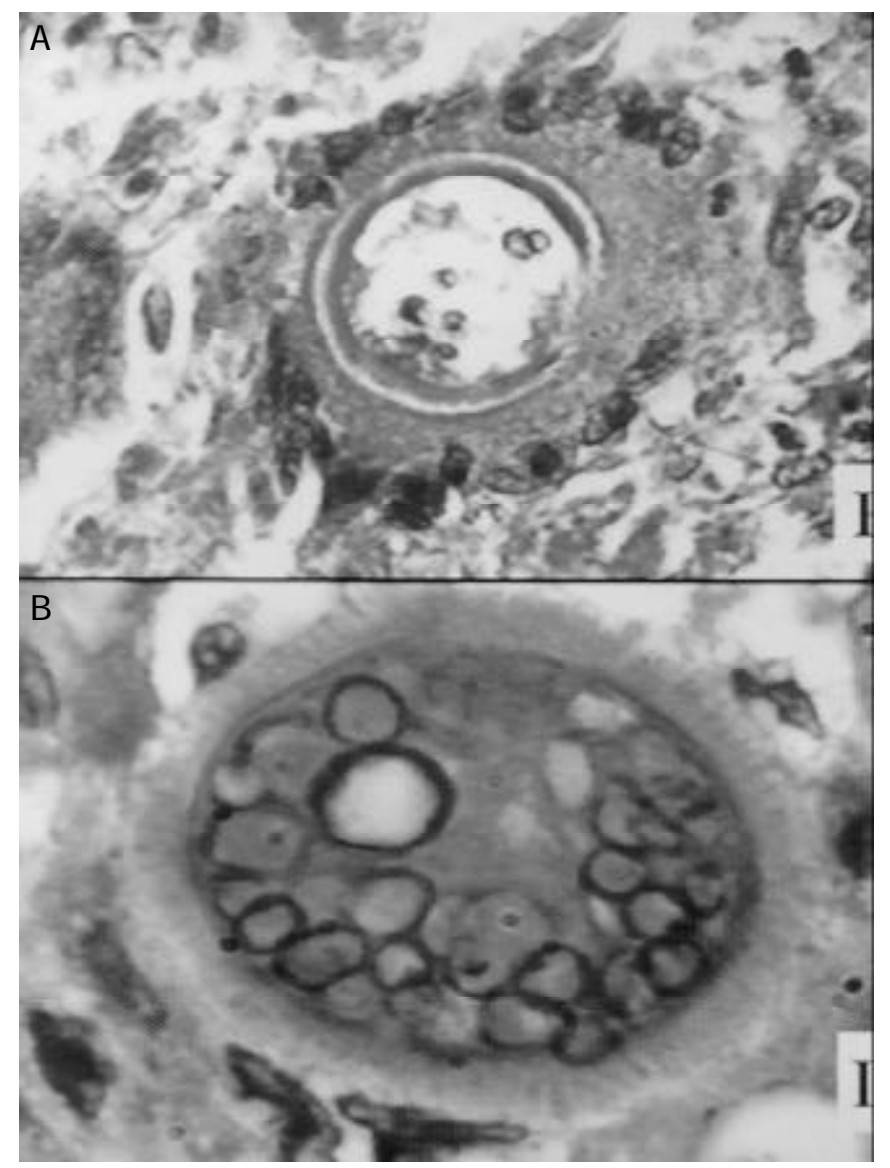

Figura 3 - A) Material obtido de tecido pulmonar evidenciando Coccidioides immitis sob a forma de esférula com ruptura em sua parede (microscopia óptica, PAS, 40x). B) Amostra do mesmo material, evidenciando esférula com paredes íntegras (microscopia óptica, PAS, 100x). 


\section{DisCUSSÃO}

A coccidioidomicose foi reconhecida como patologia distinta a partir de $1892^{(3)}$ e como infecção fúngica desde $1900^{(4)}$. Trata-se de doença endêmica com distribuição geográfica relativamente restrita a áreas de clima árido e semi-árido, onde o solo é usualmente alcalino, com salinidade elevada e baixos índices pluviométricos, condições propícias à proliferação de seu agente etiológico: Coccidioides immitis ${ }^{(4)}$. Não por acaso, a quase totalidade de casos de coccidioidomicose registrados no Brasil ocorreu na região Nordeste ${ }^{(3)}$.

Em 1994, Wanke(1) descreveu o primeiro surto epidêmico de coccidioidomicose pulmonar no Brasil, em Oeiras, $\mathrm{PI}$, onde três pacientes, após participarem de caçada a tatus, apresentaram febre e sintomas respiratórios. Relato semelhante foi descrito por Silva et al. em 1997, no município de Aiuaba, $\mathrm{CE}$, onde outros quatro casos da doença foram registrados após caçada semelhante ${ }^{(5)}$. Em 1995, Diógenes et al. verificaram, em inquérito epidemiológico com esferulina realizado no interior do Estado do Ceará, positividade de $11,5 \%$ (não detectaram presença de coccidioidomicose doença) ${ }^{(5)}$. O tatu, espécie de mamífero utilizado no Nordeste como alimento, ao ser perseguido penetra em sua toca; os caçadores, então, escavam o solo até capturar o animal, podendo assim ficar suscetíveis à inalação maciça do artroconídio (forma infectante do $C$. immitis).

Após chegar aos pulmões, o artroconídio inicia sua fase parasítica sob forma de esférulas de paredes espessadas contendo endósporos, cada um dos quais poderá formar uma nova esférula, resultando em uma reprodução exponencial ${ }^{(4)}$

Em $60 \%$ dos casos os indivíduos infectados pelo $C$. immitis não apresentam sintomas ou o fazem sob forma indistinguível de uma infecção de trato respiratório superior. No outro espectro da doença, os pacientes desenvolvem desde o típico quadro de febre, adinamia, sudorese, tosse produtiva e dor pleurítica, geralmente duas a três semanas após exposição, até doença extrapulmonar com padrão miliar, acometendo principalmente pele, articulações e meninges, na maioria das vezes após um ano de infecção ou mais tardiamente nos casos de imunossupressão(4). A apresentação radiológica varia desde infiltrados alveolares ou reticulonodulares com ou sem derrame pleural, até múltiplas cavidades, podendo complicarse com empiema e fístulas broncopleurais.

A maior dificuldade em diagnosticar a infecção consiste em não considerá-la ${ }^{(4)}$. O fungo cresce facilmente em meios de cultura usuais, em três a sete dias. Além da cultura outro método para definição de diagnóstico é a demonstração de esférulas em tecido parasitado de pacientes ou cobaia inoculada, ficando os testes sorológicos e a visualização direta a partir de escarro como métodos auxiliares.

A terapia antifúngica em infecções agudas, em quadros leves a moderados, não é obrigatória, visto que na maioria das vezes os sintomas regridem espontaneamen$t e^{(6)}$. Naqueles pacientes que desenvolvem forma pulmonar ou critérios de gravidade, o tratamento está indicado e consiste na utilização dos azóis orais (cetoconazol, fluconazol, itraconazol), ou até anfotericina B (sobretudo em acometimento meníngeo) $)^{(6)}$. A duração do tratamento ainda é fruto de controvérsia, mas os relatos de altas taxas de recidiva após a interrupção da terapia sugerem a manutenção da medicação por seis ou mais meses.

O presente caso alerta-nos para possibilidade diagnóstica de coccidioidomicose em pacientes com história de exposição a solos potencialmente contaminados, como o semi-árido do Nordeste, alterações radiológicas compatíveis e sintomas respiratórios.

\section{REFERÊNCIAS}

1. Wanke B. Coccidioidomicose. Rev Soc Bras Med Trop 1994;27(Supl 4):375-378.

2. Martins MA, Araújo EMP, Kuwakino MS, Heins-Vaccari EM, Del Negro GMB, Vozza Júnior JA, et al. Coccidioidomycosis in Brazil: a case report. Rev Inst Med Trop São Paulo 1997;39:299-304.

3. Posadas A. Un nuevo caso de micoses fungoidea com psorospermias. An Circ Med Argent 1892;15:585-597.

4. Stevens DA. Coccidioidomycosis. N Engl J Med 1993;332:1077-1082.

5. Silva LCL da, Nunes LMA, Sidrim JJC, Rios-Gonçalves AJ. Coccidioidomicose pulmonar aguda. Primeiro surto epidêmico descrito no Ceará. Segundo no Brasil. J Bras Med 1997;72:49-66.

6. Galgiani JN. Coccidioidomycosis: a regional disease of national importance. Rethinking approaches for control. Ann Intern Med 1999;130: 293-300.

7. Gomes OM, Serrano RRP, Pradel HOV, Moraes NLTB, Varella ALB, Fiorelli AI, et al. Coccidioidomicose pulmonar. Primeiro caso nacional. Rev Assoc Med Bras 1978;24:167-168.

8. Vianna H, Passos HV, Sant'ana AV. Coccidioidomicose. Relato do primeiro caso em nativo ocorrido no Brasil. Rev Inst Med Trop São Paulo 1979;21:51-55.

9. Kuhl IA, Kuhl G, Londero A, Diógenes MJN, Ferreira MF. Coccidioidomycosis laríngea. Relato de caso. Rev Bras Otorrinolaringol 1996; 62:48-51

10. Martins CA de S, Faivichenco S, Azevedo MO, et al. Coccidioidomicose adquirida no Brasil. Relato de caso como micose oportunística. Resumo do Congresso Brasileiro de Infectologia; 1997. Salvador. Resumo 394 